\title{
Reflexões acerca da sustentabilidade no âmbito da gestão de empreendimentos hoteleiros
}

\section{Reflections about sustainability in the management of enterprises hotelkeepers}

\section{Maria Claudia Mancuelho Malta, Milton Augusto Pasquotto Mariani, Dyego de Oliveira Arruda}

\begin{abstract}
RESUMO
O ambiente, a sociedade e a cultura são ativos para o desenvolvimento da atividade turística, onde os vários agentes que compõem o trade turístico das localidades - dentre eles, os empreendimentos hoteleiros - não podem se furtar a essas questões. Sendo assim, este trabalho propõe-se a analisar as práticas de sustentabilidade na gestão de empreendimentos hoteleiros sediados na cidade de Campo Grande (MS). Para tanto, foi proposta uma pesquisa exploratória, de abordagem qualitativa, em forma de estudo de caso, com entrevistas semiestruturadas aos gerentes de seis hotéis do território em análise. Constatou-se que a sustentabilidade nos hotéis investigados encontra-se em estado inicial, sobretudo por conta da falta de informações acerca de seus aspectos constitutivos. Ademais, os maiores níveis de ações sustentáveis são evidenciados em hotéis pertencentes a grandes redes. Logo, sugere-se o acirramento da difusão do conceito; bem como o efetivo incentivo para sua implantação como método de gestão organizacional contribuindo no estímulo ao estabelecimento de relações harmoniosas entre as diversas atividades econômicas, o ambiente, a cultura e as especificidades socioespaciais dos territórios.
\end{abstract}

PALAVRAS-CHAVE: Sustentabilidade; Hotelaria; Turismo.

\section{ABSTRACT}

This paper starts from the presupposition that the environment, society and culture are active in the development of tourism, where the various actors that make up the tourist trade of the towns - among them, the hotel businesses - cannot forget to watch these issues. Thus, this paper proposes to analyze the practices of sustainability in the management of hotel businesses, using a sample of hotels in the city of Campo Grande, in the state of Mato Grosso do Sul (Brazil) as a case study. To that end, we proposed an exploratory and qualitative approach, in the form of case study, with semi-structured interviews to managers of six hotels in the territory in question. The interviews were transcribed and analyzed through content analysis. It was found that sustainability in the hotels are in your initial state, mainly due to the lack of information about its constituent aspects. Moreover, it was noted that higher levels of sustainable actions are observed in hotels belonging to hotel networks. Thus, it is suggested the intensification of the diffusion of the concept, and the effective promotion of its implementation as a method of organizational management - helping in the process of encouraging the establishment of harmonious relations between the different economic activities, the environment, the culture and the other socio-spatial characteristics of the territories.

KEYWORDS: Sustainability; Hospitality; Tourism. 


\section{Introdução}

A supremacia e consolidação do sistema capitalista enquanto modo de produção dominante - muito embora tenha incorrido em uma série de incrementos técnico-produtivos na obtenção de bens e serviços - resultou em uma notória problemática socioambiental e econômica. A estagnação dos mercados dos países desenvolvidos, o distanciamento cada vez mais notório entre ricos e pobres, além da ampliação nos níveis de degradação ambiental sugerem, conjuntamente, a existência de entraves à perpetuação do atual modo de vida e de consumo, incitando reflexões quanto aos possíveis mecanismos (sejam públicos ou privados) para a regulação deste verdadeiro paradigma (STIGLITZ, 2002; HALWEIL; NIERENBERG, 2011).

Nota-se que somente nas últimas três décadas do século $X X$ a preocupação socioambiental e econômica ganhou uma conotação evidentemente prática, entrando definitivamente na seara das políticas públicas governamentais e - mais recentemente - no âmbito das práticas de gestão empresariais (BARBIERI, 2007).

Neste ínterim, a consequência natural do amadurecimento das reflexões acerca dos métodos de gestão dos recursos naturais finitos; bem como das tônicas do modelo de desenvolvimento vigente, resultou na concepção do conceito de sustentabilidade - que perfaz a base de um modo de desenvolvimento socioeconômico calcado no atendimento das necessidades do presente consubstanciada à possibilidade das gerações futuras atenderem também as suas próprias necessidades (WCED, 1987; TACHIZAWA; ANDRADE, 2008).

Neste novo paradigma de gestão dos recursos socioambientais e econômicos, a atividade do turismo se apresenta como um segmento que deve ser essencialmente voltado à sustentabilidade, pois o meio ambiente e as culturas locais são importantes receptáculos para as práticas do turismo - exercendo atratividade nos visitantes e necessitando, portanto, de iniciativas que visem à sua manutenção (GILET et al., 2008).

Seguindo por este caminho, nota-se que as empresas hoteleiras - por constituírem relevantes agentes que compõem o trade turístico ${ }^{1}$ - também se inclinam às dinâmicas da sustentabilidade. Observa-se que o setor hoteleiro está diretamente relacionado às características socioculturais e econômicas dos locais, funcionando como receptor e disseminador da cultura tradicional, e fonte de geração de renda ao território. Ademais, há empreendimentos hoteleiros que se localizam em áreas de delicado ecossistema, o que - em consonância aos outros fatores supracitados indicam a importância da temática da sustentabilidade no seio da gestão dos empreendimentos hoteleiros.

Assim sendo, considerando as supracitadas observações, e partindo da premissa de que o setor hoteleiro nutre estreita relação com o desenvolvimento de iniciativas comprometidas com os princípios da sustentabilidade, o presente trabalho tem como objetivo geral revelar as práticas sustentáveis aplicadas na gestão de empreendimentos hoteleiros sediados na cidade de Campo Grande, capital do Estado de Mato Grosso do Sul.

Em linhas gerais, o município de Campo Grande é um relevante destino 
turístico no Centro Oeste brasileiro, tendo sua vocação majoritariamente calcada nos setores de negócio e eventos. Ademais, nota-se ainda que o território em tela é corredor e ponto de partida para o turismo em dois destinos turísticos de relevância nacional - a região de Bonito e Serra da Bodoquena; e do Pantanal sul-matogrossense.

Desta feita, a problemática que embasou o desenvolvimento de toda a pesquisa resumiu-se no seguinte questionamento: como se manifestam as práticas de sustentabilidade na gestão dos empreendimentos hoteleiros da cidade de Campo Grande, no Mato Grosso do Sul?

Vale ponderar que as reflexões acerca da problemática de pesquisa acima descrita podem representar importantes caminhos para o estabelecimento de um verdadeiro marco, calcado em práticas estratégicas que sejam ambientalmente equilibradas, socialmente justas e economicamente rentáveis, não só no segmento de hotelaria, mas em outras atividades sociais e econômicas que podem representar potencial impacto ao meio ambiente e à sociedade, como um todo.

Em suma, o presente texto está estruturado em quatro partes - além desta introdução. $\mathrm{Na}$ primeira parte apresenta-se o referencial teórico referente aos conceitos e dimensões da sustentabilidade e desenvolvimento sustentável, aplicandoos no contexto do turismo e, por conseguinte, no seio da hotelaria. Na segunda parte, descrevem-se os procedimentos metodológicos adotados no desenvolvimento da pesquisa, além do tipo de pesquisa, as fontes para a coleta de dados e a forma utilizada para a análise desses dados. Na terceira parte, apresenta-se a análise dos dados obtidos com a pesquisa; além dos resultados alcançados no desenvolvimento desta pesquisa. Por fim, na quarta e última parte, algumas considerações finais são tecidas, com a consequente exposição de contribuições, limitações e direcionamentos para investigações futuras.

\section{Desenvolvimento sustentável e sustentabilidade}

Entender e categorizar denominadores comuns acerca dos conceitos de sustentabilidade e desenvolvimento sustentável perfaz uma tarefa de difícil - senão impossível - execução. Quental et al. (2011) sugerem a necessidade de um rigor científico e metodológico na utilização dos conceitos em tela, sobretudo por conta do contemporâneo aparecimento da sustentabilidade e do desenvolvimento sustentável como verdadeiros paradigmas capazes de solucionar problemas existenciais e transgeracionais da humanidade.

Neste sentido, Lelé (1991) - à guisa de conceituações de caráter mais definitivo - entende que o desenvolvimento sustentável, como o próprio termo indica, perfaz um composto de dois conceitos distintos: sustentabilidade e desenvolvimento. A sustentabilidade, por si só, é avaliada a partir da existência de condições sociais e ecológicas necessárias para a subsistência humana, em um determinado nível de bem estar que possibilite o florescimento das gerações futuras; ao passo que o desenvolvimento é interpretado como um processo de mudança caracterizado pelo crescimento 
constante nos níveis de consumo (seja de bens ou de serviços).

Neste ínterim, reunindo as concepções semânticas dos supracitados termos expostos por Lelé (1991), o desenvolvimento sustentável seria calcado no crescimento constante do consumo das populações, consubstanciado com uma dinâmica intergeracional, ou seja, enraizado em um tipo de consumo que não impeça a disposição dos recursos - naturais, humanos, econômicos e etc. - às futuras gerações.

Desta feita, rememorando o relatório Brundtland (intitulado 'Nosso Futuro Comum'), elaborado pela Comissão Mundial de Meio Ambiente e Desenvolvimento (CMMAD) em 1987, preconiza-se que o desenvolvimento sustentável tipifica-se pelo chamado fator intergeracional - que perfaz um senso de preocupação em se estabelecer padrões de vida e de crescimento contemporâneos que não inviabilizem sobremaneira os possíveis padrões de vida e de consumo futuros (WCED, 1987).

Nota-se que a preocupação quanto ao desenvolvimento sustentável surge, no correr do século XX, por conta de constatações inequívocas inerentes à pressão sobre os recursos naturais, que cada vez mais dão mostras do seu caráter frágil e finito. Ademais - muito por conta das dinâmicas do modo de produção dominante - assistese a uma explosão da pobreza e desigualdades sociais (sobretudo nos países em desenvolvimento); bem como a proliferação de crises econômicas nas nações de economia mais madura (EHRLICH, 1968; HARDIN, 1968).

Assim sendo, diante deste quadro, são necessários mecanismos não raro coercitivos com vistas ao estímulo rumo à adoção de ações calcadas no desenvolvimento sustentável. Dentre estes estímulos (sobretudo no que tange à gestão dos recursos naturais) estão a definição de direitos de propriedade dos bens comuns; estipulação de capacidades de carga dos ambientes naturais; além da definição de multas aos agentes que ultrapassem os limites de utilização dos recursos socioambientais (HARDIN, 1968). São mecanismos que, em suma, perpassam pelo poder coercitivo do Estado e das políticas públicas.

Porém, Buysse e Verbeke (2003) reiteram que, extrapolando o papel do Estado e das políticas públicas, as empresas também cumprem uma importante função na adoção voluntária e estratégica de práticas calcadas na sustentabilidade em seus modelos de negócios. Hart e Milstein (2003) e Lovins et al. (2011), complementando o argumento proposto, ressaltam as dinâmicas da sustentabilidade como uma importante estratégia de criação de valor aos stakeholders ${ }^{2}$ direta ou indiretamente vinculados às organizações.

Para Jappur et al. (2008), no que se refere à sustentabilidade corporativa em específico, deve-se incluir entre seus objetivos estratégicos o cuidado com o meio ambiente, o bem-estar das partes interessadas e a constante melhoria da sua própria reputação. Nesse sentido, Holliday et al. (2002) afirmam que a organização sustentável deve ir além do modelo tradicional de retorno sobre os ativos financeiros, obrigando-se a envolver o sucesso da comunidade e dos stakeholders.

Por ser um conceito dinâmico, muitos esquemas de desagregação por dimensões foram propostos à sustentabilidade. Em suma, o número de suas dimensões varia de acordo com o autor. Sachs (2002), um dos mais conhecidos, subdividiu a sus- 
tentabilidade em cinco dimensões básicas: social, econômica, ecológica, espacial e cultural. Posteriormente houve a inclusão de outras dimensões, tais como a política e a institucional. Entretanto, no âmbito das organizações, o chamado 'núcleo duro' da sua contribuição para com o desenvolvimento sustentável passou a consistir em três dimensões básicas: a econômica, a social e a ambiental. A redução das dimensões não implica perda ou abandono das outras dimensões; mas sim a concentração delas no conhecido 'Tripé da Sustentabilidade' (ou Triple-Bottom-Line, nos termos em língua inglesa) (ELKINGTON, 1998).

O surgimento de indicadores para mensurar o desenvolvimento sustentável é fruto do reconhecimento de que outras dimensões devem medir o desenvolvimento de um território, rompendo com a hegemonia do uso de indicadores econômicos como critério para a tomada de decisões individuais ou coletivas. Van Bellen (2004) aponta os índices Ecological Footprint Method, Dashboard of Sustainability e Barometer of Sustainability como as ferramentas mais relevantes no contexto internacional para a avaliação da sustentabilidade (GUIMARÃES; FEICHAS, 2009).

No setor empresarial são aplicados índices e indicadores de sustentabilidade nacionais e internacionais. Entre eles, podemos destacar a Global Reporting Initiative (GRI), os Dow Jones Sustainability Indexes (DJSI), o Índice de Sustentabilidade Empresarial (ISE) e os Environmental Performance Indicators (EPI's) ${ }^{3}$ (ALENCASTRO et al., 2011).

Como indicadores sustentáveis também se podem mencionar as séries ISO 9001 (gestão da qualidade), ISO 14001 (gestão ambiental), AS 8000 (gerenciamento social), ABNT/NBR 16001 (gestão da responsabilidade social). Estas séries tem o objetivo de orientar as empresas quanto à programação e manutenção de seus sistemas de gestão, calcados em questões socioambientais e econômicas.

\section{Sustentabilidade aplicada ao turismo e hotelaria}

Para Gonçalves (2004), o setor do turismo, em geral, e a hotelaria, em particular, têm a obrigação e a responsabilidade de fazer da ética ambiental parte integrante de suas metas organizacionais e gerenciais, já que o sucesso dos seus negócios depende em boa parte da 'saúde' do meio ambiente (BUCKLEY, 2010).

Além de pensar no aspecto de que a natureza, a sociedade e a cultura são ativos para o financeiro da empresa, o setor hoteleiro precisa também levar em conta que a abertura de diálogo com o mercado e, principalmente, com o público-alvo, é cada vez mais urgente e necessário (LARA, 2001). Um ponto interessante a convergir é a satisfação dos desejos dos indivíduos e o que é melhor para seus clientes e para a sociedade. Acrescentar a gestão sustentável aumenta o mercado de consumidores atingido, já que há os chamados 'consumidores verdes', que perfazem uma parcela em ascensão no mercado de bens e serviços social e ecologicamente responsáveis.

À medida que o perfil do turista e suas exigências sofrem transformações, o setor precisa usar da criatividade para oferecer produtos que satisfaçam ao novo turista (COOPER et al., 2007). A qualidade de uma destinação turística vem sendo ava- 
liada com base na originalidade de suas atrações ambientais e no bem-estar que elas proporcionam aos visitantes. Portanto, o marketing ambiental passa a constituir uma importante arma para os responsáveis pela oferta turística das localidades receptoras (RUSCHMANN, 2008).

Os hotéis que adotam uma postura sustentável procuram atitudes menos danosas ao ambiente através da reavaliação de suas ações e da conscientização de seus membros. Tais dinâmicas são auferidas, sobretudo, através da otimização do uso dos recursos, do reaproveitamento e reciclagem dos resíduos - maneiras simples de repensar o processo e tentar racionalizá-lo. Em função da contenção do desperdício, economiza-se nos custos operacionais, crescem as oportunidades de mercado derivados das novas práticas ambientais, a imagem da corporação é fortalecida, além de causar um impacto positivo no moral dos empregados, aumentando o comprometimento dos clientes internos e o orgulho em ser parte da corporação (ENZ; SINGUAW, 1999).

Silva et al. (2006) confirmaram as relações entre a gestão ambiental e o desempenho organizacional do setor hoteleiro. Segundo esses autores as empresas hoteleiras que demonstram melhores níveis de desempenho organizacional tendem a usar mais e melhor as práticas de gestão ambiental.

No âmbito econômico, os gestores do turismo e da hotelaria devem possuir conhecimento detalhado dos impactos econômicos derivados dessa atividade, uma vez que os turistas gastam seu dinheiro com uma variedade de mercadorias e serviços, tais como: transportes, alimentação, bebida, comunicação e entretenimento (BARROCO, 2004).

Priorizando o aspecto social, os gestores deverão respeitar a autenticidade sociocultural das comunidades anfitriãs, conservando patrimônio cultural e valores tradicionais, contribuindo para o entendimento mútuo e tolerância; assegurar a viabilidade das operações econômicas de longo prazo, proporcionando benefícios socioeconômicos para todos os stakeholders, incluindo emprego estável, oportunidades de geração de renda e serviços sociais para as comunidades, contribuindo para a minimização da pobreza; fomentar a informação e participação dos stakeholders, para garantir a ampla participação e a construção do consenso; manter a satisfação do turista em níveis elevados e garantir uma experiência significativa para estes, aumentando a sua consciência sobre as questões relativas à sustentabilidade (CARDOSO; TASCHNER, 2005).

Porém, atingir o turismo sustentável é um processo que requer monitoramento constante dos impactos, introduzindo as medidas preventivas e/ou corretivas sempre que necessário.

Não obstante, Benner e Tushman (2003) salientam que a questão da normatização técnica e padronização de processos, sobretudo em setores e ambientes de negócios marcadamente instáveis, inibem a exploração de novas oportunidades através de inovações radicais, não raro bloqueando - consequentemente - a criação de novos bens/serviços que atendam demandas já manifestadas ou latentes nos consumidores. 


\section{Procedimentos metodológicos}

Dada a realidade socialmente construída e multidisciplinar que está por trás das temáticas relativas à sustentabilidade; bem como considerando o objetivo delimitado para o presente trabalho, entende-se que o método qualitativo se torna o mais adequado para os propostos esquadrinhados.

A investigação qualitativa "(...) emprega diferentes concepções filosóficas; estratégias de investigação; e métodos de coleta, análise e interpretação dos dados" (CRESWELL, 2010, p.206). Procura-se, a partir de uma abordagem qualitativa, entender o fenômeno estudado de forma holística e minuciosa, não raro valendo-se da apreensão do contexto sob o qual os fenômenos investigados ocorrem.

Quanto aos fins, a pesquisa constitui-se como exploratória e descritiva. Vergara (2007) salienta que a pesquisa exploratória cumpre o fim de analisar, in loco, os atoreschave para a elucidação do tema - uma vez que não há demasiado material documentado acerca do mesmo; ao passo que a pesquisa descritiva tem como escopo caracterizar e levantar (e consequentemente confirmar ou refutar) determinadas hipóteses de pesquisa.

A estratégia de investigação utilizada foi o estudo multicasos. Este método é muito produtivo para estimular a compreensão e sugerir hipóteses e questões para a pesquisa, investigando as conjunturas, além dos pontos de convergência e/ou divergência dos casos selecionados para a investigação (MATTAR, 2001; VERGARA, 2007; MARTINS; THEÓFILO, 2007).

O instrumento de coleta de dados, no escopo deste artigo, foi um protocolo contendo questões norteadoras e indicadores para cada dimensão estudada (econômica, social e ambiental), constituindo-se, portanto, de um roteiro semiestruturado para a entrevista; bem como para a observação direta das características dos casos selecionados para estudo (YIN, 2010).

A Tabela 1, além de apresentar os indicadores de análise de cada dimensão do 'tripé da sustentabilidade', traz as questões norteadoras que compuseram o instrumento de coleta de dados.

Os empreendimentos hoteleiros investigados foram selecionados de acordo com uma abordagem intencional e não-probabilística, justificada pela premissa de se analisar três hotéis pertencentes a redes hoteleiras e três hotéis de origem familiar - abstraindo-se, portanto, possíveis características e pontos de divergência desses dois grandes grupos de hotéis. As entrevistas foram realizadas e gravadas durante visita aos hotéis pesquisados, no mês de outubro de 2010. Os atores da entrevista foram os gerentes dos empreendimentos hoteleiros que tiveram disponibilidade em contribuir com a pesquisa.

De fundamental esclarecimento é o fato de que os nomes dos hotéis pesquisados foram mantidos em sigilo, e estão nomeados de $H(A)$ a $H(F)$ nas análises realizadas neste trabalho. Os hotéis pertencentes a redes hoteleiras estão indicados por $\mathrm{H}(\mathrm{A})$, $H(B)$ e $H(D)$; ao passo que os hotéis não pertencentes a redes são chamados de $H(C)$, $H(E)$ e $H(F)$. 
Tabela 1: Protocolos de estudo de caso.

Table 1: Protocols of the case study.

\begin{tabular}{|c|c|c|}
\hline Dimensão & Indicadores de Análise & Questões do Protocolo \\
\hline \multirow{9}{*}{ SOCIAL } & Responsabilidade social & \multirow{6}{*}{$\begin{array}{l}\text { Quais políticas e progra- } \\
\text { mas são desenvolvidos } \\
\text { para promover a melhoria } \\
\text { nos padrões de vida da } \\
\text { sociedade? }\end{array}$} \\
\hline & $\begin{array}{l}\text { Equiparação salarial entre negros, pardos, homens e mulhe- } \\
\text { res com a mesma função. }\end{array}$ & \\
\hline & $\begin{array}{l}\text { Benefícios básicos (alimentação, transporte, tempo de des- } \\
\text { canso e etc.). }\end{array}$ & \\
\hline & $\begin{array}{l}\text { Rotatividade de funcionários em relação à média do merca- } \\
\text { do }\end{array}$ & \\
\hline & Índice de satisfação dos funcionários & \\
\hline & Índice de satisfação dos clientes & \\
\hline & Capacitação e atualização profissional & \multirow{3}{*}{$\begin{array}{l}\text { Quais ações e projetos } \\
\text { são trabalhados para pro- } \\
\text { mover a cultura local? }\end{array}$} \\
\hline & $\begin{array}{l}\text { Programas e treinamentos para a redução de acidentes de } \\
\text { trabalho }\end{array}$ & \\
\hline & Programas de identidade cultural & \\
\hline \multirow{9}{*}{ AMBIENTAL } & Reciclagem & \multirow{5}{*}{$\begin{array}{l}\text { A estratégia ambiental da } \\
\text { empresa engloba quais } \\
\text { fatores ligados à preserva- } \\
\text { ção dos recursos naturais? }\end{array}$} \\
\hline & Tecnologias limpas e silenciosas & \\
\hline & Tratamento de afluentes líquidos & \\
\hline & Reaproveitamento de afluentes líquidos & \\
\hline & Produtos ecologicamente corretos & \\
\hline & Legislação ambiental & \multirow{4}{*}{$\begin{array}{c}\text { Como são implantadas as } \\
\text { políticas de racionalização } \\
\text { dos recursos naturais? }\end{array}$} \\
\hline & Certificação pela norma ISO 14.000 & \\
\hline & Fontes alternativas de economia energética & \\
\hline & Racionalização de água e energia & \\
\hline \multirow{6}{*}{ ECONÔMICA } & Crescimento de resultados financeiros & \multirow{4}{*}{$\begin{array}{c}\text { De que forma as estraté- } \\
\text { gias em sustentabilidade } \\
\text { impactam nos stakehol- } \\
\text { ders? }\end{array}$} \\
\hline & Transparência nas ações próprias da empresa & \\
\hline & Aquisição de projetos adequados à sustentabilidade & \\
\hline & $\begin{array}{l}\text { Existência de pessoa ou cargo que analise a dimensão sus- } \\
\text { tentável do hotel }\end{array}$ & \\
\hline & Pesquisas sobre sustentabilidade & \multirow{2}{*}{$\begin{array}{l}\text { Quais as atitudes dos sta- } \\
\text { keholders em relação às } \\
\text { ferramentas de gestão } \\
\text { sustentável? }\end{array}$} \\
\hline & Disposição em pagar mais pelo serviço ambiental & \\
\hline
\end{tabular}

Fonte: Adaptado de Santos (2009). Elaborado pelos autores.

Source: Adapted from Santos (2009). Prepared by the authors.

Durante a entrevista, procurou-se coletar dados também através da observação direta informal, que segundo Yin (2010) é frequentemente útil para proporcionar informação adicional sobre o tópico estudado. As entrevistas foram gravadas, transcritas e analisadas por meio da técnica de análise de conteúdo, que tem como escopo lançar mão de 
ferramentas sistemáticas e objetivas de descrição dos conteúdos das mensagens e relatos coletados em interlocução com os atores que se pretende investigar (BARDIN, 2009).

Por fim, no que se refere ao território selecionado para investigação, vale ressaltar que o município de Campo Grande - capital do Estado de Mato Grosso do Sul - é um importante corredor logístico das atividades de ecoturismo e turismo de natureza praticadas mais especificamente na região do Pantanal e de Bonito/Serra da Bodoquena. Quanto aos empreendimentos hoteleiros, nota-se a existência de mais de 2.753 unidades habitacionais e 5.524 leitos localizados na capital de Mato Grosso do Sul (SISGRAN, 2011; FUNDTUR, 2011).

A Figura 1 ilustra a localização do Estado de Mato Grosso do Sul, e do município de Campo Grande, em particular:

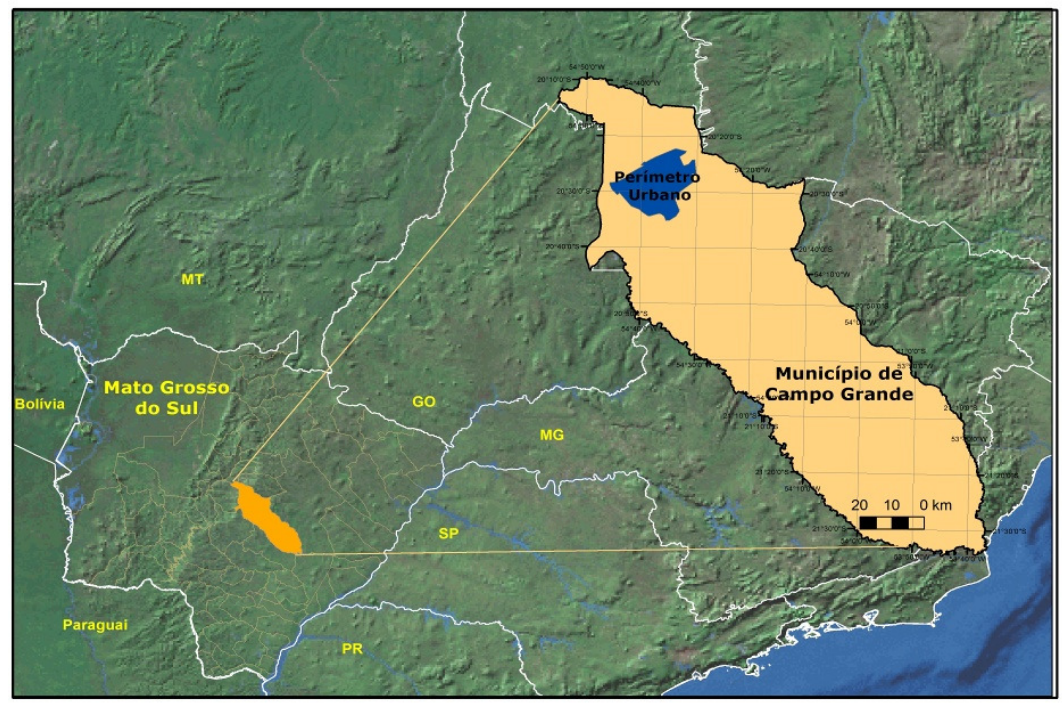

Figura 1: Localização de Mato Grosso do Sul e de Campo Grande (2013).

Fonte: Elaborada por Fábio Martins Ayres.

Figure 1: Location of Mato Grosso do Sul and Campo Grande (2013).

Source: Prepared by Fábio Martins Ayres.

Vale registrar, ademais, que são relevantes e urgentes as reflexões acerca das práticas de sustentabilidade praticadas pelos empreendimentos hoteleiros de Campo Grande, sobretudo considerando os possíveis impactos positivos que este setor pode relegar à completude da atividade turística praticada no Mato Grosso do Sul, de tal modo que o turismo regional tipifique-se por uma dinâmica socioeconômica e ambientalmente equilibrada.

\section{Análise dos dados coletados na pesquisa empírica}

Antes de se debruçar nas questões específicas às dimensões da sustentabilidade elencadas no escopo do presente trabalho, faz-se necessário apresentar um panorama geral das características dos empreendimentos hoteleiros investigados, conforme segue na Tabela 2: 
Tabela 2: Características gerais dos empreendimentos hoteleiros investigados.

Table 2: General characteristics of enterprises hotelkeepers investigated.

\begin{tabular}{|c|c|c|c|c|}
\hline Hotel & $\begin{array}{c}\text { Origem do } \\
\text { Hotel }\end{array}$ & Tipo & Características & Valor da diária \\
\hline \multirow{6}{*}{ Hotel A } & \multirow{6}{*}{$\begin{array}{l}\text { Pertencente a } \\
\text { uma rede }\end{array}$} & \multirow{6}{*}{ Superior } & 101 Unidades Habitacionais e 202 Leitos & \multirow{6}{*}{$\begin{array}{l}\text { A partir de } R \$ \\
129,00\end{array}$} \\
\hline & & & Estacionamento & \\
\hline & & & Restaurante e Bar & \\
\hline & & & Adaptações para cadeirantes & \\
\hline & & & Lanchonete $24 \mathrm{~h}$ & \\
\hline & & & Possui Site & \\
\hline \multirow{6}{*}{ Hotel B } & \multirow{6}{*}{$\begin{array}{l}\text { Pertencente a } \\
\text { uma rede }\end{array}$} & \multirow{6}{*}{ Luxo } & 87 Unidades Habitacionais e 176 Leitos & \multirow{6}{*}{$\begin{array}{l}\text { A partir de } R \$ \\
150,00\end{array}$} \\
\hline & & & Estacionamento & \\
\hline & & & Restaurante e Bar & \\
\hline & & & Adaptações para cadeirantes & \\
\hline & & & Centro de ginástica, sala de jogos e de reuniões & \\
\hline & & & Possui Site & \\
\hline \multirow{6}{*}{ Hotel C } & \multirow{6}{*}{$\begin{array}{l}\text { Não pertencen- } \\
\text { te a rede }\end{array}$} & \multirow{6}{*}{ Luxo } & 140 Unidades Habitacionais e 260 Leitos & \multirow{6}{*}{$\begin{array}{c}R \$ 255,00 a \\
R \$ 450,00\end{array}$} \\
\hline & & & Estacionamento & \\
\hline & & & Possui dois restaurantes & \\
\hline & & & Adaptações para cadeirantes & \\
\hline & & & $\begin{array}{l}\text { Possui sala de jogos, de ginástica, além de seis salas } \\
\text { para convenções }\end{array}$ & \\
\hline & & & Possui Site & \\
\hline \multirow{7}{*}{ Hotel D } & \multirow{7}{*}{$\begin{array}{l}\text { Pertencente a } \\
\text { uma rede }\end{array}$} & \multirow{7}{*}{ Luxo } & 80 Unidades Habitacionais e 161 Leitos & \multirow{7}{*}{$\begin{array}{l}\text { A partir de } \mathrm{R} \$ \\
184,00\end{array}$} \\
\hline & & & Estacionamento & \\
\hline & & & Adaptações para cadeirantes & \\
\hline & & & Possui restaurante & \\
\hline & & & $\begin{array}{l}\text { Possui quadra de tênis, sala de jogos, de ginástica e } \\
\text { cinco salas para convenções }\end{array}$ & \\
\hline & & & Apresenta serviços médicos e lavanderia & \\
\hline & & & Possui Site & \\
\hline \multirow{6}{*}{ Hotel E } & \multirow{6}{*}{$\begin{array}{l}\text { Não pertencen- } \\
\text { te a uma rede }\end{array}$} & \multirow{6}{*}{ Superior } & 94 Unidades Habitacionais e 140 Leitos & \multirow{6}{*}{$\begin{array}{c}R \$ 130,00 a \\
R \$ 275,00\end{array}$} \\
\hline & & & Estacionamento & \\
\hline & & & Possui bar & \\
\hline & & & Adaptações para cadeirantes & \\
\hline & & & Possui quatro salas para convenções & \\
\hline & & & Possui Site & \\
\hline \multirow{7}{*}{ Hotel F } & \multirow{7}{*}{$\begin{array}{l}\text { Não pertencen- } \\
\text { te a uma rede }\end{array}$} & \multirow{7}{*}{ Superior } & 128 Unidades Habitacionais e 193 Leitos & \multirow{7}{*}{$\begin{array}{c}R \$ 170,00 a \\
R \$ 215,00\end{array}$} \\
\hline & & & Estacionamento & \\
\hline & & & Restaurante & \\
\hline & & & Bar & \\
\hline & & & Adaptações para cadeirantes & \\
\hline & & & Possui sala para convenções & \\
\hline & & & Possui Site & \\
\hline
\end{tabular}

Fonte: Elaborado pelos autores, a partir da pesquisa empírica.

Source: Prepared by authors, based on empirical research. 
Pode-se observar, a partir de uma análise do quadro supracitado, que os empreendimentos hoteleiros pesquisados apresentam características similares, localizando-se em padrão luxo/superior. Uma particularidade interessante refere-se ao fato de que os hotéis de maior porte (com maior quantidade de Unidades Habitacionais e Leitos) são aqueles não pertencentes a redes. Ademais, esses empreendimentos apresentam maior número de salas para reuniões/convenções, o que revela uma diversificação de suas atividades para além da mera função de meio de hospedagem.

Os tópicos abaixo elencados trazem as investigações acerca do enquadramento desses empreendimentos hoteleiros às dimensões básicas da sustentabilidade.

\section{Análise da dimensão social}

Dentre os empreendimentos hoteleiros pesquisados, aferiu-se que aqueles que se autodeclararam pertencentes a redes hoteleiras (à exceção do Hotel D) possuíam, em maior grau, algum tipo de ação ou projeto social quando comparados aos hotéis não pertencentes às redes hoteleiras. Estes últimos afirmam não possuir projetos específicos para esse fim. Porém, ao se investigar cada um dos itens que compõem as ações sociais no seio dos empreendimentos hoteleiros não pertencentes a redes percebeu-se que - mesmo em menor escala - há a evidência de determinadas ações com algum caráter social, não raro esporádicas e revestidas de estratégias de marketing e divulgação de seus produtos/serviços.

No que tange à especificidade dessas ações sociais, destacam-se a participação em iniciativas calcadas na própria dinâmica de rede de empreendimentos (tais como o auxílio contínuo à instituições de caridade); bem como ações isoladas de doações a entidades filantrópicas (no caso dos hotéis não pertencentes a redes).

Desta feita, confirmam-se alguns direcionamentos propostos por Tachizawa e Andrade (2008), sobretudo quando estes autores salientam o tamanho da organização (considerando, nos casos analisados, as redes como um todo, nas quais os hotéis A, B e D estão inseridos) como condição preliminar para que o empreendimento se vincule a algum tipo de ação social. O mesmo também é válido - conforme se verá mais adiante - quando se analisa a dimensão ambiental.

Quando questionados sobre equiparação dos salários dos funcionários, todos os seis empreendimentos hoteleiros pesquisados afirmaram possuir tal preocupação. Um dos gerentes - hotel $\mathrm{F}$ - mencionou que há a preocupação em se contratar portadores de necessidades especiais (sobretudo como forma de inclusão social desse público). Outro gestor (Hotel A) por sua vez informou que o hotel está isento pela lei de contratar funcionários portadores de necessidades especiais, tendo em vista a quantidade de funcionários devidamente registrados, razão pela qual esta preocupação não é evidente no seio da gestão do empreendimento. Portanto, mais uma vez corroborase a constatação de que o porte da organização pode delimitar o seu nível de engajamento quanto a algumas dinâmicas sociais da sustentabilidade.

Ainda considerando a questão dos portadores de necessidade especiais, percebeu-se que todos os empreendimentos hoteleiros possuem acesso a portadores de deficiência física ou cadeirantes. 
Sobre os benefícios, atualização profissional e treinamentos destinados aos colaboradores, os gerentes relataram aplicar 0 que a legislação os obriga (concedendo, porém, os benefícios básicos obrigatórios em lei, tais como alimentação, transporte e horários para descanso). Cultiva-se também, na sua maioria, algum tipo de treinamento ou atualização profissional destinado a função exercida pelo funcionário. Percebe-se que os hotéis pertencentes às redes, em maior grau, dedicam-se a especializar seus funcionários, considerando as imposições da marca; bem como o nível de exigência de seus clientes e demais stakeholders.

Quando questionados sobre prevenção de acidentes no trabalho, percebeu-se que estas ações ocorrem em forma de orientações nos treinamentos (ação preventiva). Somente os hotéis B e C alegaram possuir algum tipo de programa para se evitar acidentes laborais - porém, são programas caracterizados por baixo nível de complexidade e abrangência.

Sobre a rotatividade dos funcionários, dois empreendimentos hoteleiros, percebeu-se que somente nos hotéis $\mathrm{C} \mathrm{e} E$ (ambos não pertencente a redes hoteleiras) há uma relativa rotatividade de funcionários, sobretudo nas funções de menor complexidade e - consequentemente - menores níveis de exigências por parte do empregador. Os demais empreendimentos hoteleiros consideraram a rotatividade de funcionários como sendo baixo; ambos com uma política de 'demitir somente em último caso'.

Analisando o repasse de informações sobre a sustentabilidade por parte da gestão do empreendimento hoteleiro para com os funcionários e hóspedes, percebeuse que dentre os gerentes que visualizam alguma prática de sustentabilidade na sua gestão, dois gerentes dos hotéis pertencentes a redes acreditam no trabalho de conscientização da gestão voltada à sustentabilidade do empreendimento sobre seus funcionários e/ou hospedes.

Com relação ao índice de satisfação dos funcionários, duas das empresas em redes (hotéis $A$ e B) possuem pesquisa para medi-las. Os demais gerentes afirmam não possuir instrumentos para medir a satisfação dos funcionários, apesar de alguns gerentes afirmarem possuí-las em conversas informais (através de métodos também informais de mensuração e consulta).

Os agentes pesquisados, em sua maioria, não souberam apontar projetos com algum tipo de incentivo cultural. Apenas o gerente do empreendimento hoteleiro $D$ qualificou a ação de informação da recepção como uma forma de divulgar a cultura local.

Logo, percebe-se que há pouca informação quanto às práticas culturais que podem ser estabelecidas pelos empreendimentos hoteleiros. O foco cultural ainda é bem distante e não há associação entre a cultura e a sustentabilidade e, por conseguinte, entre a cultura e geração de lucro advinda de seu fomento. Durante as entrevistas, a alimentação e a decoração do hotel não foram sequer lembradas como elementos difusores da cultura local.

A Tabela 3 sumariza os pontos evidentes em cada um dos empreendimentos hoteleiros investigados, quanto à dimensão social da sustentabilidade. 
Malta, M.C.M.; Mariani, M.A.P.; Arruda, D.O.

Tabela 3: Análise da dimensão social da sustentabilidade nos empreendimentos hoteleiros.

Table 3: Analysis of the social dimension of sustainability in the enterprises hotelkeepers.

\begin{tabular}{|c|c|c|c|c|c|c|}
\hline \multirow{2}{*}{ Indicadores da Dimensão Social } & \multicolumn{6}{|c|}{ Hotéis } \\
\hline & A & B & C & D & $\mathbf{E}$ & $\mathbf{F}$ \\
\hline Responsabilidade social & $\mathrm{X}$ & $\mathrm{X}$ & - & - & - & - \\
\hline $\begin{array}{c}\text { Equiparação salarial entre negros, pardos, homens } \\
\text { e mulheres com a mesma função. }\end{array}$ & $\mathrm{X}$ & $\mathrm{X}$ & $\mathrm{X}$ & $X$ & $\mathrm{X}$ & $\mathrm{X}$ \\
\hline $\begin{array}{c}\text { Benefícios básicos (alimentação, transporte, tempo } \\
\text { de descanso e etc.). }\end{array}$ & $\mathrm{X}$ & $\mathrm{X}$ & $\mathrm{X}$ & $X$ & $\mathrm{X}$ & $\mathrm{X}$ \\
\hline $\begin{array}{l}\text { Rotatividade de funcionários em relação à média } \\
\text { do mercado }\end{array}$ & Baixo & Baixo & $\begin{array}{l}\mathrm{Na} \\
\text { média }\end{array}$ & Baixo & $\begin{array}{l}\mathrm{Na} \\
\text { média }\end{array}$ & Baixo \\
\hline $\begin{array}{l}\text { Pesquisa quanto ao índice de satisfação dos fun- } \\
\text { cionários }\end{array}$ & $X$ & $\mathrm{X}$ & - & - & - & - \\
\hline Índice de satisfação dos clientes & - & - & - & - & - & - \\
\hline Capacitação e atualização profissional & $\mathrm{X}$ & $\mathrm{X}$ & $\mathrm{X}$ & $\mathrm{X}$ & - & - \\
\hline $\begin{array}{l}\text { Programas e treinamentos para a redução de aci- } \\
\text { dentes de trabalho }\end{array}$ & - & $\mathrm{X}$ & $X$ & - & - & - \\
\hline Programas de identidade cultural & - & - & - & $\mathrm{X}$ & - & - \\
\hline
\end{tabular}

Fonte: Elaborado pelos autores, a partir da pesquisa empírica.

Source: Prepared by authors, based on empirical research.

Vale ponderar, por fim, que nenhum dos empreendimentos pesquisados apresentou avaliações quanto ao índice de satisfação dos clientes e demais stakeholders quanto à sua atuação organizacional, o que denota o baixo nível de preocupação dos empreendimentos quanto à aferição de seus respectivos impactos diretos e indiretos na sociedade onde estão inseridos.

\section{Análise da dimensão ambiental}

Um dos fatores de atratividade do setor hoteleiro é o próprio ambiente no qual está inserido. Nesse sentido, a preocupação com os recursos socioambientais locais é inevitável para uma estratégia de longo prazo de sobrevivência e perpetuação dessas empresas.

Neste interim, os empreendimentos hoteleiros pesquisados afirmaram possuir algumas ações voltadas a esse fim. Mesmo que alguns não possuam projetos específicos, de forma simplista as estratégias ambientais estão presentes em ações que vislumbram economia de recursos. Mais uma vez, os empreendimentos hoteleiros pertencentes a redes mostraram maior conhecimento acerca do assunto.

Quando perguntados sobre reciclagem, apenas o empreendimento hoteleiro (E) afirmou não possuir nenhum tipo de iniciativa nesse sentido. Os demais citaram reaproveitamento de papéis e procedimentos para coleta seletiva de lixo.

O reaproveitamento do óleo de cozinha também foi uma questão lembrada 
dentre as atividades ambientais desempenhadas por alguns empreendimentos hoteleiros. Há doações desse item; assim como de lixo reciclável, para empresas terceirizadas. Houve também afirmação por parte de um gerente que o valor da reciclagem é revertido para festas entre funcionários. Posto isto, demonstra-se a inter-relação existente entre as dimensões da sustentabilidade.

Sobre produtos ecologicamente corretos, a maioria dos gerentes relatou possuir preocupação em adquiri-los. Dentre os três empreendimentos hoteleiros não pertencentes a redes, dois afirmaram que não há preocupações nesse sentido (hotéis E e F).

A energia e a água são preocupações em todos os empreendimentos hoteleiros pesquisados. Todas estas organizações possuem fontes alternativas de energia - como a energia solar ou gerador. Alguns apostam em bloqueadores de energia e poços artesianos para gerar economia de recursos econômicos.

Sobre padrões e normas, uma das empresas hoteleiras contatadas possuía ISO 14001 e outras duas estão em processo de implantação de certificações. As demais não alegaram nenhuma preocupação em possuir certificação em normas ambientais.

Não obstante, percebe-se que na grande maioria dos empreendimentos hoteleiros pesquisados não há monitoramento constante dos impactos causados pelas ações não sustentáveis e muito menos atuações preventivas ou corretivas. Não há indicadores que constituam uma carta de navegação, como aborda Guimarães e Feichas (2009).

Observou-se que o setor hoteleiro possui algumas ações específicas, tais como os programas de reutilização de toalhas e roupas de cama por parte dos hóspedes que ficam nos quartos em um período maior que um dia. Sobre isso, nota-se que dois dos seis empreendimentos pesquisados não aderem a esse tipo de iniciativa, $H(E)$ e $H(F)$. Interessante salientar que ambas as empresas hoteleiras não pertencem a redes.

A Tabela 4 sumariza os elementos da dimensão ambiental evidentes nos empreendimentos hoteleiros pesquisados.

Tabela 4: Análise da dimensão ambiental da sustentabilidade nos empreendimentos hoteleiros.

Table 4: Analysis of environmental sustainability in the enterprises hotelkeepers.

\begin{tabular}{|c|c|c|c|c|c|c|}
\hline \multirow{2}{*}{ Indicadores da Dimensão Ambiental } & \multicolumn{5}{|c|}{ Hotéis } \\
\cline { 2 - 7 } & A & B & C & D & E & F \\
\hline Reciclagem & $\mathrm{X}$ & $\mathrm{X}$ & $\mathrm{X}$ & $\mathrm{X}$ & - & $\mathrm{X}$ \\
\hline Tecnologias limpas e silenciosas & - & - & - & - & - & - \\
\hline Tratamento de efluentes líquidos & - & - & - & - & - & - \\
\hline Reaproveitamento de efluentes líquidos & - & - & - & - & - & - \\
\hline Produtos ecologicamente corretos & $\mathrm{X}$ & $\mathrm{X}$ & $\mathrm{X}$ & $\mathrm{X}$ & - & - \\
\hline Legislação ambiental & & & & & & \\
\hline Certificação pela norma ISO 14.000 & $\mathrm{X}$ & - & - & - & - & - \\
\hline Fontes alternativas de economia energética & $\mathrm{X}$ & $\mathrm{X}$ & $\mathrm{X}$ & $\mathrm{X}$ & $\mathrm{X}$ & $\mathrm{X}$ \\
\hline Racionalização de água e energia & $\mathrm{X}$ & $\mathrm{X}$ & $\mathrm{X}$ & $\mathrm{X}$ & $\mathrm{X}$ & $\mathrm{X}$ \\
\hline
\end{tabular}

Fonte: Elaborado pelos autores, a partir da pesquisa empírica.

Source: Prepared by authors, based on empirical research. 
Deve-se destacar que, nos hotéis pesquisados, não há preocupação em utilização de tecnologias limpas; bem como inexistem programas de tratamento e reutilização de efluentes líquidos. Vale mais uma vez ressaltar que a maioria dos programas de cunho ambiental existentes nos empreendimentos hoteleiros investigados surgiu e ainda perdura a reboque da primazia da economia de recursos econômicos e minimização de possíveis custos operacionais (a despeito, notadamente, de uma preocupação ambiental de cunho essencialmente intergeracional por parte da organização, seus funcionários e demais stakeholders).

\section{Análise da dimensão econômica}

Dentre os gerentes dos empreendimentos hoteleiros investigados observou-se que metade acredita no impacto econômico positivo para o hotel advindo de ações sustentáveis, quais sejam especificamente os hotéis $A, B$ e $C$. Os demais não conseguiram mensurar os impactos econômicos gerados pelas ações sustentáveis, por não possuírem projetos nesse sentido; ou por não conseguirem medir as ações aplicadas.

Identificou-se que não há contabilidade formal com relação às práticas sustentáveis que os empreendimentos hoteleiros de Campo Grande exercem. Tal constatação vai contra às orientações de Barbieri e Cajazeira (2009) quando abordam que é necessário que a empresa avalie os passivos ocultos para obter o resultado líquido referente à dimensão econômica da sustentabilidade.

Mesmo não sendo feito formalmente, a mensuração economia conseguida com a aplicação de práticas sustentáveis é um dado que pode ser percebido pelos gestores, até mesmo através das ações dos seus funcionários. Neste sentido, alguns gerentes mencionaram acerca do impacto econômico da sustentabilidade no que tange aos reflexos para seus funcionários.

A sustentabilidade também pode ser mensurada através da imagem gerada pelas ações dos empreendimentos aos consumidores. Ou seja, as atitudes positivas por parte dos clientes frente às práticas sustentáveis podem ser percebidas pelos gestores e transformadas em vantagens competitivas por eles utilizáveis. No entanto, nesse quesito, houve impasse na resposta com relação à sensibilidade dos clientes à questão sustentável. A metade dos gestores acredita que os hóspedes valorizam as práticas sustentáveis (gestores dos hotéis $A, B$ e C).

A outra metade, no entanto, não consegue medir a valorização dos hóspedes frente às ações de sustentabilidade aplicadas nos hotéis, até por não possuírem iniciativas essencialmente focadas nesse aspecto.

Importante salientar que se os gestores não conseguem acreditar que o cliente é capaz de valorizar a sustentabilidade, também não acreditarão na diferenciação advinda destas práticas. E, portanto, não apostarão na gestão voltada para a sustentabilidade nesse setor, até que consigam mensurar a economia financeira, ou que haja intervenção da legislação pertinente.

Sobre pesquisa e gerência designada a projetos sustentáveis, obteve-se a respos- 
ta de que não houve pesquisa na área de sustentabilidade em nenhum dos empreendimentos hoteleiros investigados.

A Tabela 5 representado ilustra as especificidades da dimensão econômica da sustentabilidade, evidentes nos empreendimentos hoteleiros investigados:

Tabela 5: Análise da dimensão econômica da sustentabilidade nos empreendimentos hoteleiros.

Table 5: Analysis of the economic dimension of sustainability in the enterprises hotelkeepers.

\begin{tabular}{|c|c|c|c|c|c|c|}
\hline \multirow{2}{*}{ Indicadores da Dimensão Econômica } & \multicolumn{6}{|c|}{ Hotéis } \\
\hline & $\mathbf{A}$ & B & $\mathbf{C}$ & D & $\mathbf{E}$ & $\mathbf{F}$ \\
\hline $\begin{array}{c}\text { Crescimento de resultados financeiros decorrentes da } \\
\text { sustentabilidade }\end{array}$ & $X$ & $X$ & $\mathrm{X}$ & - & - & - \\
\hline Transparência nas ações próprias da empresa & $\mathrm{X}$ & $\mathrm{X}$ & $\mathrm{X}$ & $\mathrm{X}$ & $\mathrm{x}$ & $\mathrm{X}$ \\
\hline Aquisição de projetos adequados à sustentabilidade & - & - & - & - & - & - \\
\hline $\begin{array}{c}\text { Existência de pessoa ou cargo que analise a dimensão } \\
\text { sustentável do hotel }\end{array}$ & - & - & - & - & - & - \\
\hline Pesquisas sobre sustentabilidade & - & - & - & - & - & - \\
\hline Disposição em pagar mais pelo serviço ambiental & $x$ & $x$ & $x$ & - & - & - \\
\hline
\end{tabular}

Fonte: Elaborado pelos autores, a partir da pesquisa empírica.

Source: Prepared by authors, based on empirical research.

Pode-se perceber, a partir da observação do quadro acima, que os hotéis estudados não apresentam a preocupação de adquirir projetos e dinâmicas gerenciais calcadas nos princípios da sustentabilidade (ou seja: não se preocupam em se inserir em cadeias de suprimentos de bens/serviços que sejam sustentáveis). Ademais, são inexistentes contabilidades e mensurações específicas às externalidades decorrentes de praticas sustentáveis, o que denota o aspecto incipiente desta temática do âmbito da gestão dos empreendimentos hoteleiros campo-grandenses investigados.

\section{Considerações finais}

Constatou-se - mediante o desenvolvimento de toda a pesquisa - que apesar de a sustentabilidade em todos os empreendimentos hoteleiros investigados ser uma temática deveras evidente, as informações e práticas foram mais robustas nos empreendimentos hoteleiros pertencentes a redes. Os gerentes destas organizações se mostraram mais seguros com relação à exposição dos assuntos relativos à sustentabilidade e, portanto, também deram maior credibilidade à esta questão.

De uma forma geral, pode-se concluir que a sustentabilidade nos empreendimentos hoteleiros da cidade de Campo Grande ainda se encontra em seu estágio inicial, sobretudo pelo fato de haver informação incompleta sobre o assunto por parte dos gestores entrevistados; bem como por não serem elaborados pesquisas e cálculos mais pragmáticos sobre sustentabilidade por esses hotéis, com os respectivos ativos e passivos decor- 
rentes das ações adotadas. Logo, as ações entabuladas pelos hotéis investigados relacionam-se intrinsecamente à economia de recursos econômicos (em detrimento da premissa prioritária geração de valor socioambiental aos possíveis stakeholders da organização).

Não obstante - no contexto investigado - a sustentabilidade está atrelada principalmente às ações que a lei determina ou em que há economia financeira comprovada por terceiros (energia e água). Assim, trata-se de uma prática que não se apresenta como ideologia ou diferencial intrínseco ao negócio.

Portanto, dadas essas questões, o presente artigo revela-se como um verdadeiro 'mapa de navegação' aos agentes direta ou indiretamente ligados aos empreendimentos hoteleiros em Campo Grande, sugerindo as falhas no que tange à adoção da sustentabilidade no âmbito deste setor; bem como os caminhos para a tomada de decisões estratégicas com vistas à consecução da sustentabilidade, em todos os seus matizes constitutivos.

Sugere-se - como importantes caminhos para futuros estudos - a adoção de amostras quantitativas e aleatórias acerca dos empreendimentos a serem investigados, com vistas à elaboração de inferências e guias de atuação mais genéricos e conclusivos.

\section{Referências bibliográficas}

ALENCASTRO, J. et al. Indicadores de Desenvolvimento Sustentável. Pollution Engineering. v.03; p.22, Jan/Mar. 2011.

BARBIERI, J.C. Gestão Ambiental Empresarial: Conceitos, Modelos e Instrumentos. São Paulo: Editora Saraiva, 2007.

BARBIERI, J.C.; CAJAZEIRA, J.E.R. Responsabilidade Social Empresarial e Empresa Sustentável: da teoria à prática. São Paulo: Editora Saraiva, 2009.

BARDIN, L. Análise de Conteúdo. Lisboa: Edições 70, 2009.

BARROCO, H.E. Uma reflexão sobre o planejamento turístico-cultural e sustentabilidade. Revista turismo \& desenvolvimento, Campinas, vol. 03; n‥ 01, p. 9-16, 2004.

BENNER, M.J.; TUSHMAN, M.L. Exploitation, exploration, and process management: the productivity dilemma revisited. Academy of Management Review, vol. 28, no 02, p. 238256, 2003.

BUCKLEY, R. Environmental Inputs and Outputs in Ecotourism: Geotourism with a Positive Triple Bottom Line? Journal of Ecoturism, vol. 02, no. 01, p. 76-82, 2010.

BUYSSE, K.; VERBEKE, A. Proactive Environmental Strategies: A Stakeholder Management Perspective. Strategic Management Journal, vol. 24, p. 453-470, 2003.

CARDOSO, R.C; TASCHNER, G. Dimensões sociais do turismo sustentável: estudo sobre a contribuição dos resorts de praia para o desenvolvimento das comunidades locais. 2005. Tese - Doutorado em Administração. Escola de Administração de Empresas de São Paulo, Fundação Getúlio Vargas. São Paulo/SP: EAESP/FGV, 2005.

COOPER, C. et al. Turismo: princípios e práticas. 3aㅡ ed. Porto Alegre: Brookman, 2007. 
CRESWELL, J.W. Projeto de pesquisa: métodos qualitativo, quantitativo e misto. $3^{\underline{a}}$ edição. Porto Alegre: Editora Artmed, 2010.

EHRLICH, P. The population bomb. New York: Ballantine Books, 1968.

ELKINGTON, J. Partnerships from cannibals with forks: The triple bottom line of 21 stcentury business. Environmental Quality Management, vol. 08, № 01, p. 37-51, 1998.

ENZ, C.A.; SIGUAW, J. A.; Best hotel environmental practices: Cornell Hotel and Restaurant Administration. Quarterly Review, p. 72-77, Oct/1999.

FUNDTUR - FUNDAÇÃO DE TURISMO DO MATO GROSSO DO SUL. Perfil de Mato Grosso do Sul. Campo Grande: FUNDTUR/MS, 2011.

GILET, A.L.; ORFILA-SINTES, F.; CHULIÁN, M.F. La proactividad de la estrategia medioambiental del sector hotelero: una aplicación en Baleares. In: III Congreso de la Asociación Hispano-Portuguesa de Economía de los Recursos Naturales y Ambientales. Anales. Palma (Illes Balears), 2008. 31p.

GONÇALVES, L.C. Gestão Ambiental em Meios de Hospedagem. São Paulo: Aleph, 2004.

GUIMARÃES, R.P.; FEICHAS, S.A. Q. Desafios na construção de indicadores de sustentabilidade. Ambiente e Sociedade. Campinas, v. XII, n. 2, p. 307-323, Jul-dez. 2009.

HALWEIL, B.; NIERENBERG, D. Charting a new path to eliminating hunger. In: THE WORLDWATCH INSTITUTE. 2011 State of the World: Innovations that Nourish the Planet. New York/London: W.W. Norton \& Company, 2011.

HARDIN, G. The Tragedy of the Commons. Science Review, vol. 162, p. 1243-1248, 1968.

HART, S.L.; MILSTEIN, M.B. Creating sustainable value. Academy of Management Review, vol. 17, $\mathrm{n} \div .02,2003$.

HOLLIDAY, C.; SCHMIDHEINY, S.; WATTS, P. Cumprindo o prometido: casos de sucesso de desenvolvimento sustentável. Rio de Janeiro: Campos, 2002.

JAPPUR, R.F. et al. A visão de especialistas sobre a sustentabilidade corporativa frente às diversas formações de cadeias produtivas. Revista Produção Online, Florianópolis, vol. 07, ํㅡ. 03, 2008.

LARA, S.B. Marketing \& vendas na hotelaria. 2ํㅡ. São Paulo: Futura, 2001.

LELÉ, S.M. Sustainable development: a critical review. World Development, vol. 19, ํ․ 06, p. 607-621, 1991.

LOVINS, A.B.; LOVINS, L.H.; HAWKEN, P. A road map for natural capitalism. Harvard Business Review, vol. 85, no. 7/8, p. 145-158, 2011.

MARTINS, G.A.; THEÓPHILO, C.R. Metodologia da investigação científica para ciências sociais aplicadas. São Paulo: Editora Atlas, 2007.

MATTAR, F.N. Pesquisa de Marketing. São Paulo: Editora Atlas, 2001. 
QUENTAL, N.; LOURENÇO, J.M.; SILVA, F.N. Sustainability: characteristics and scientific roots. Environment, Development and Sustainability Review, vol.13, nํ.02, p. 257-276, 2011.

RUSCHMANN, D. Turismo e Planejamento Sustentável: a proteção do meio ambiente. Campinas: Editora Papirus, 2008.

SACHS, I. Caminhos para o desenvolvimento sustentável. Rio de Janeiro: Ed. Garamond, 2002.

SANTOS, M.G. Análise da sustentabilidade nas indústrias frigoríficas exportadoras de carne bovina do Estado de Mato Grosso do Sul. 2009. Dissertação - Mestrado em Agronegócios. Departamento de Economia e Administração, Universidade Federal de Mato Grosso do Sul. Campo Grande/MS: DEA/UFMS, 2009.

SEVERINO, A.J. Metodologia do trabalho científico. São Paulo: Editora Cortez, 1996.

SILVA, L.M.T.; SILVA, M.P.; ENDERS, W.T. Gestão Ambiental e Desempenho Organizacional: Um Estudo de suas Relações no Setor Hoteleiro. In: XXX Encontro da ANPAD. Anais. Salvador/BA: ENANPAD, 2006.

SISGRAN, Sistema Municipal de Indicadores Georreferenciados para o Planejamento e a Gestão de Campo Grande/MS. Perfil de Campo Grande. Campo Grande: SISGRAN, 2011.

STIGLITZ, J. Globalization and its discontents. New York: W.W. Norton Press, 2002.

TACHIZAWA, T. Gestão Ambiental e Responsabilidade Social Corporativa. São Paulo: Editora Atlas, 2008.

TACHIZAWA, T.; ANDRADE, O.B. Gestão socioambiental: estratégias na nova era da sustentabilidade. Rio de Janeiro: Elsevier, 2008.

VAN BELLEN, H.M. Desenvolvimento Sustentável: uma descrição das principais ferramentas de avaliação. Ambiente \& Sociedade, vol. 07; nํ. 01, 2004.

VERGARA, S.C. Projetos e Relatórios de Pesquisa em Administração. 9ạ. Ed. São Paulo: Editora Atlas, 2007.

WCED - WORLD COMMISSION ON ENVIRONMENT AND DEVELOPMENT. Our common future. Oxford: Oxford University Press, 1987.

YIN, R.K. Estudo de Caso: Planejamento de Método. Porto Alegre: Editora Bookman, 2005.

\section{Agradecimentos}

Especiais agradecimentos devem ser direcionados ao Programa de Pós-Graduação em Administração da Universidade Federal de Mato Grosso do Sul (PPGAd/UFMS), por auxiliar no desenvolvimento da pesquisa. Ademais, são dedicados os créditos e agradecimentos ao Geógrafo e Mestre em Desenvolvimento Local Fábio Martins Ayres, pelo auxílio na elaboração do mapa, e pelas discussões quanto ao material que deu corpo ao presente artigo. Quaisquer possíveis erros e/ou omissões que porventura existam neste material são de inteira responsabilidade dos autores. 


\section{Notas:}

1 O trade turístico perfaz o conjunto de agentes que compõem a infraestrutura que possibilita a prática do turismo. Dentre os agentes componentes do trade turístico estão hotéis, bares e restaurantes, agências de turismo e etc.

${ }^{2}$ Os stakeholders (ou 'partes interessadas', em português) são agentes que se ligam direta ou indiretamente à gestão das organizações, devendo estar de acordo com as práticas de coordenação e governança exercidas por essas organizações.

${ }^{3} \mathrm{O}$ presente trabalho, por questões de foco e escopo, se furta à explicação das especificidades dos supracitados indicadores. Para maiores detalhes e informações, consultar Van Bellen (2004) e Allencastro et al (2011).

Maria Claudia Mancuelho Malta: Universidade Federal de Mato Grosso do Sul, Campo Grande, MS, Brasil.

Email: minimalta@hotmail.com

Link para o currículo Lattes: http://lattes.cnpq.br/6276197262789514

Milton Augusto Pasquotto Mariani: Universidade Federal de Mato Grosso do Sul, Campo Grande, MS, Brasil.

Email: miltmari@terra.com.br

Link para o currículo Lattes: http://lattes.cnpq.br/0935409945176042

Dyego de Oliveira Arruda: Universidade Federal de Mato Grosso do Sul, Campo Grande, MS, Brasil.

Email: dyego.arruda@gmail.com

Link para o currículo Lattes: http://lattes.cnpq.br/5222976964204691

Data de submissão: 13 de dezembro de 2012

Data de recebimento de correções: 10 de abril de 2013

Data do aceite: 12 de abril de 2013

Avaliado anonimamente 